\title{
ОЦЕНКА ЭКОЛОГИЧЕСКОЙ УСТОЙЧИВОСТИ ПОВЕРХНОСТНЫХ ВОД ЗАПАДНОЙ СИБИРИ
}

\author{
Ж. А. Тусупбеков, Н. Л. Ряполова \\ Омский государственный аграрный университет имени П.А. Столыпина, Россия \\ Поступила в редакиию 25 марта 2019 г.
}

\begin{abstract}
Аннотация: Рассмотрены актуальные вопросы сопоставления природно-ресурсного и техногенного потенциалов речных бассейнов Западной Сибири на основе данных о местном и транзитном речном стоке, выполнена оценка водных ресурсов и водообеспеченности территорий с целью выявления экологического потенциала поверхностных вод.

Проанализированы методики определения эколого-географических характеристик, на основе которых сделан вывод об их значении в системе нормирования антропогенной нагрузки. Приведены результаты расчетов удельной экологической техноемкости ресурсов поверхностных вод $\left(\mathrm{t}_{\text {пв }}\right)$, усл.т/км² в средний год на территории Западной Сибири и зависимость их от широты местности.
\end{abstract}

Ключевые слова: водные ресурсы, водообеспеченность, речные бассейны, потенциал территории, техногенная нагрузка, экологическая устойчивость, поверхностные воды.

\section{Assessment of the environmental sustainability of surface waters in Western Siberia}

\section{J. A. Tusupbekov, N. L. Ryapolova}

\begin{abstract}
Topical issues of comparison of natural-resource and technogenic potentials of river basins of Western Siberia on the basis of data on local and transit river flow are considered, the assessment of water resources and water availability of territories for the purpose of revealing of ecological potential of surface waters is carried out.

Methods of determination of ecological and geographical characteristics on the basis of which the conclusion about their value in the system of regulation of anthropogenic load is made are analyzed. The results of calculations of the specific environmental Technoelast surface water resources $\left(\mathrm{t}_{\mathrm{\pi B}}\right)$, in the middle year in Western Siberia and their dependence on the latitude.
\end{abstract}

Key words: water resources, water availability, river basins, potential of a territory, anthropogenic load, environmental sustainability, surface water.

\section{ВВЕДЕНИЕ}

Непрерывная возобновляемость, а также возможность вовлечения и использования в процессе природопользования являются особенностью водных ресурсов. Из этого следует, что анализ и оценка водных ресурсов с точки зрения сопоставления природного и техногенного потенциалов территории имеет неоспоримое научное и практическое значение для комплексного использования водных ресурсов региона и их охраны.

Цель исследования - количественная оценка водных ресурсов Западной Сибири и интегральное количественное определение эколого-географических параметров водных ресурсов территорий региона и соизмерение их экологической ус-

() Тусупбеков Ж. А., Ряполова Н. Л., 2019 тойчивости при современном уровне техногенной нагрузки на рассматриваемые компоненты природной среды.

Водные ресурсы Западной Сибири преимущественно формируются за счет местного и транзитного речного стока с сопредельных территорий (таблица 1). Различия природно-климатических условий рассматриваемой территорий и, прежде всего, ресурсов теплообеспеченности и увлажнения, определяют неодинаковые доли местного и транзитного речного стока в общей сумме водных ресурсах территорий Западной Сибири. В частности, выполненные расчеты водообеспеченности Западной Сибири показали, что суммарные водные ресурсы Челябинской, Новосибирской, Омской и Курганской областей от 71,0 до 86,0\% представлены транзитным стоком рек Оби, Иртыша и 
Среднемноголетние водные ресурсы и водообеспеченность региона

\begin{tabular}{|c|c|c|c|c|c|c|}
\hline \multirow{2}{*}{$\begin{array}{c}\text { Субъект } \\
\text { Федерации }\end{array}$} & \multirow{2}{*}{$\begin{array}{c}\text { Пло- } \\
\text { щадь } \\
\text { тыс. км² }\end{array}$} & \multicolumn{2}{|c|}{$\begin{array}{c}\text { Среднемноголетние } \\
\text { водные ресурсы, км³/год }\end{array}$} & \multirow{2}{*}{$\begin{array}{c}\text { Населе- } \\
\text { ние, } \\
\text { тыс. чел } \\
\text { [3] }\end{array}$} & \multicolumn{2}{|c|}{$\begin{array}{c}\text { Водообеспеченность } \\
\text { водными ресурсам, } \\
\text { тыс. м год/чел }\end{array}$} \\
\hline & & $\begin{array}{l}\text { суммар- } \\
\text { ные [1] }\end{array}$ & $\begin{array}{c}\text { в т. ч. } \\
\text { местного } \\
\text { стока [2] }\end{array}$ & & $\begin{array}{l}\text { суммар- } \\
\text { ными }\end{array}$ & $\begin{array}{l}\text { местного } \\
\text { стока }\end{array}$ \\
\hline Курганская обл. & 71,5 & 3,5 & 1,0 & 947,6 & 3,7 & 1,1 \\
\hline Свердловская обл. & 194,3 & 30,2 & 29,1 & 4393,8 & 6,9 & 6,6 \\
\hline Челябинская обл. & 88,5 & 7,4 & 6,2 & 3508,4 & 2,1 & 1,8 \\
\hline Тюменская обл. & 1464,2 & 583,7 & 331,6 & 3430,3 & 170,2 & 96,7 \\
\hline Республика Алтай & 92,9 & 34,0 & 34,0 & 210,7 & 161,4 & 161,4 \\
\hline Алтайский край & 168 & 55,1 & 21,1 & 2490,7 & 22,1 & 8,5 \\
\hline $\begin{array}{l}\text { Новосибирская } \\
\text { обл. }\end{array}$ & 177,8 & 64,3 & 8,97 & 2649,9 & 24,3 & 3,4 \\
\hline Омская обл. & 141,1 & 41,3 & 6,7 & 2012,1 & 20,5 & 3,3 \\
\hline Томская обл. & 314,4 & 182,3 & 72,2 & 1043,8 & 174,7 & 69,2 \\
\hline Сумма & 2712,7 & 1001,8 & 505,19 & 20687,3 & 48,4 & 24,4 \\
\hline
\end{tabular}

Тобола. Ресурсы местного стока составляют лишь незначительную часть от общего стока.

Данное обстоятельство изначально формирует риск возникновения в названных областях дефицита водных ресурсов, в свою очередь недостаток воды является фактором, так или иначе сдерживающим социально-экономическое развитие, особенно в южных и наиболее освоенных районах этих областей. Недостаток водных ресурсов, в будущем, может потребовать их территориального перераспределения.

Немаловажной проблемой является также и показатели качества поверхностных вод, которые находятся в полной зависимости от загрязненности водосборного бассейна и качества сточных вод, сбрасываемых непосредственно в водные объекты. Имеющиеся статистические данные, свидетельствуют о том, что в общем объеме сбрасываемых в водоемы сточных вод, более $40 \%$ - загрязненные [4]. По отдельным бассейнам качество сбрасываемых вод не соответствует требованиям нормативов. Так, по данным Нижне-Обского бассейнового водного управления Федерального агентства водных ресурсов [5] в результате хозяйственной деятельности ежегодно в водные объекты бассейна реки Иртыш поступает до $99 \%$ загрязненных вод от общего объема сброса сточных вод (таблица 2).

Хозяйственная деятельность на водосборных площадях и аварийные сбросы загрязняющих веществ существенно влияют на загрязнение значительного числа рек бассейна Оби (р.p. Иртыш, Тобол, Чулым, Исеть. Миасс, Полуй).
Чрезмерное влияние хозяйственной деятельности на водный объект и водосборный бассейн может привести к нарушению саморегулирующей способности компонентов геосистем и возникновению необратимых процессов в ландшафтной сфере. Причем, влияние хозяйственной деятельности на изменение параметров экосистемы значительно выше, тогда когда естественные показатели при неизменности климатических условий относительно постоянны. В связи с этим, изучение причин изменения качества природных систем при совокупном воздействии различных факторов и прогноз их развития является важной задачей и должна иметь четкую научно-методическую основу.

\section{МЕТОДИКА ИССЛЕДОВАНИЯ И ОБСУЖДЕНИЕ РЕЗУЛЬТАТОВ}

Проблема экологического нормирования антропогенных нагрузок, а также предпосылки к количественной оценке основных эколого-географических характеристик экосистем различных рангов рассматривались в работах А.А. Григорьева, А. А. Григорьева и М.И. Будыко. А в дальнейшем они нашли развитие и теоретико-методологическое обоснование в работах Т.А. Акимовой и ее соавторов. В монографии Т.А. Акимовой и В. В. Хаскина количественно определены такие понятия как «экологический потенциал», «экологическая емкость территории» и «экологическая техноемкость территории (ЭТТ)» [1]. При этом экологическая техноемкость является «обобщенной 
Показатели использования водных ресурсов в бассейне р. Иртыш

\begin{tabular}{|c|c|c|c|c|c|c|c|c|c|}
\hline \multirow[b]{2}{*}{ № } & \multirow[b]{2}{*}{ Наименование показателей } & \multirow[b]{2}{*}{ 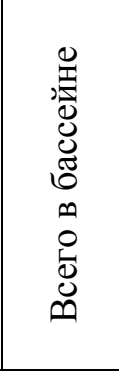 } & \multicolumn{7}{|c|}{ Распределение по субъектам РФ } \\
\hline & & & 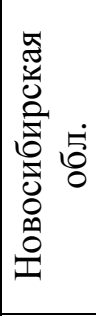 & 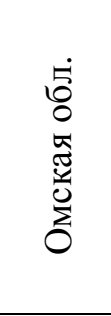 & 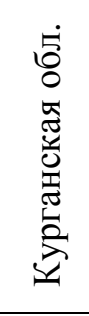 & 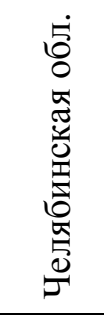 & 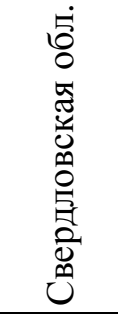 & 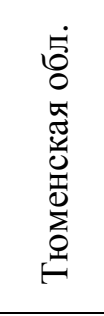 & $\sum_{x}^{O}$ \\
\hline 1 & $\begin{array}{l}\text { Количество } \\
\text { водопользователей }\end{array}$ & 3041 & 197 & 539 & 432 & 636 & 687 & 493 & 57 \\
\hline \multirow[t]{4}{*}{2} & Забор воды, млн.м ${ }^{3}$ & 2784,5 & 53,9 & 304,6 & 84,2 & 738,4 & 1149 & 422 & 32,5 \\
\hline & в том числе: & & & & & & & & \\
\hline & - поверхностных & 2164,3 & 36,1 & 288,3 & 67,5 & 658,3 & 757,4 & 354,8 & 2 \\
\hline & - подземных & 620,2 & 17,8 & 16,3 & 16,7 & 80 & 391,6 & 67,3 & 30,5 \\
\hline 3 & $\begin{array}{l}\text { Использование забранной } \\
\text { воды, млн.м }\end{array}$ & 2094,2 & 51 & 272,4 & 62,5 & 431,9 & 854,6 & 391,7 & 30,2 \\
\hline \multirow[t]{3}{*}{4} & $\begin{array}{l}\text { Сброс сточных вод в } \\
\text { поверхностные водоемы, } \\
\text { млн.м }^{3}\end{array}$ & 2171,8 & 9,5 & 210 & 56,3 & 358,2 & 1168,2 & 357,1 & 12,5 \\
\hline & в т.ч. загрязненных & 1526,5 & 9 & 207,2 & 56,1 & 351,2 & 798,5 & 99,7 & 5 \\
\hline & $\begin{array}{l}\text { доля загрязненных от } \\
\text { общего сброса сточных } \\
\text { вод,\% }\end{array}$ & 70,3 & 94,7 & 98,7 & 99,6 & 98 & 68,4 & 27,9 & 40 \\
\hline
\end{tabular}

характеристикой территории, количественно соответствующей максимальной техногенной нагрузке, которую может выдержать и переносить в течение длительного времени (годы) совокупность реципиентов и экологических систем территории без нарушения их структурных и функциональных свойств» [1, с. 194]. Количественно ЭТТ соответствует состоянию экологического равновесия между тем, что может «выдержать и переносить» экосистема и техногенной нагрузкой на эту систему. В случае превышения создавшегося природного уровня изменчивости путем антропогенного воздействия наблюдается нарушение экологической устойчивости природного комплекса территории.

В работе Н. Б. Поповой [3] впервые дана оценка экологической техноемкости и экологической емкости территорий Западно-Сибирской равнины на основе эколого-географического принципа. По разработанным ею методикам были выполнены эколого-географические характеристики и даны оценки отдельным регионам севера (Н.Р. Яхина) и юга (М.С. Чикинова) Западной Сибири.

Применительно к нормированию допустимого воздействия на водные ресурсы, а также и оценки их устойчивости к антропогенному воздействию перспективным является направление, ос- нованное на оценке экологической техноемкости поверхностных вод, расчетные значения, пространственное и временное изменение которой определяются взаимосвязью влаго- и теплообмена в ландшафтной среде $[1,2,3]$. С точки зрения исследования оценки экологической устойчивости речных поверхностных вод, в том числе малых рек и водотоков, наибольшее значение в практическом отношении имеет оценка экологической техноемкости местного стока, формирующегося в пределах каждого речного бассейна.

В не нарушенных условиях экологической среды не происходит изменения экологической устойчивости компонента геосистемы. Ухудшение естественного уровня устойчивости в большей степени связано с техногенным воздействием.

Экологическая техноемкость территории как доля общей экологической емкости территории трех компонентов среды (воздух, вода и почва), при котором сохраняется их экологическая устойчивость можно определить по следующему выражению:

$$
\ni T T_{i}=T_{i}=\sum_{1}^{3} \ni_{i} \cdot X_{i} \cdot A_{i},
$$

где ЭТT $T_{i}=T_{i}-$ экологическая техноемкость территории, выраженная в единицах массы техногенной нагрузки, усл. т/год; 
Удельная экологическая техноемкость ресурсов поверхностных вод $\left(t_{n \varepsilon}\right)$, усл.т/км² в средний год

\begin{tabular}{|l|c|c|l|c|c|}
\hline $\begin{array}{c}\text { Пункт } \\
\text { (метеостанция) }\end{array}$ & $\begin{array}{c}\text { Широта, } \\
\varphi\end{array}$ & $\begin{array}{c}t_{n в} \text { усл. } \\
\text { т/км }^{2}\end{array}$ & $\begin{array}{c}\text { Пункт } \\
\text { (метеостанция) }\end{array}$ & $\begin{array}{c}\text { Широта, } \\
\varphi\end{array}$ & $\begin{array}{c}t_{n в} \text { усл. } \\
\text { т/км }^{2}\end{array}$ \\
\hline Новый Порт & 67,73 & 4,24 & Верхотурье & 58,92 & 1,43 \\
\hline Ныда & 66,65 & 3,59 & Нижний Тагил & 57,93 & 2,03 \\
\hline Полуй & 66,03 & 3,02 & Васисс & 57,42 & 1,38 \\
\hline Уренгой & 65,97 & 2,71 & Седельниково & 56,93 & 0,84 \\
\hline Тарко-Сале & 64,95 & 3,23 & Большие Уки & 57,05 & 0,97 \\
\hline Толька & 64,03 & 2,77 & Тюкалинск & 55,9 & 0,25 \\
\hline Хале-Савой & 63,38 & 3,90 & Калачинск & 55,08 & 0,31 \\
\hline Нумто & 63,50 & 2,59 & Одесское & 54,22 & 0,19 \\
\hline Октябрьское & 62,50 & 2,64 & Русская Поляна & 53,85 & 0,13 \\
\hline Няксимволь & 62,48 & 1,84 & Александровское & 60,43 & 2,26 \\
\hline Сургут & 61,40 & 3,62 & Напас & 59,87 & 2,69 \\
\hline Кондинское & 59,67 & 1,28 & Колпашево & 58,38 & 1,98 \\
\hline Уват & 59,13 & 1,38 & Томск & 56,52 & 2,27 \\
\hline Тобольск & 58,23 & 1,39 & Каргат & 55,22 & 0,79 \\
\hline Ишим & 56,18 & 0,46 & Маслянино & 54,35 & 1,24 \\
\hline Ивдель & 60,73 & 1,57 & Баево & 53,35 & 0,13 \\
\hline
\end{tabular}

$Э_{i}$ - экологическая емкость $i$-ой среды, т/год;

$X_{i}$ - коэффициент вариации естественных колебаний содержания основной субстанции в среде; $A_{i}$ - коэффициент перевода фактической массы загрязняющего вещества в условные тонны (коэффициент относительной опасности примесей).

В уравнении (1), меняя значения экологической емкости на удельную экологическую емкость $e_{i}$, можно определить соответствующие удельные значения экологической техноемкости $t_{6}$ - приземного слоя воздуха, $t_{n \varepsilon}-$ поверхностных вод и $t_{\phi}-$ фитоценозов (усл.т/км²). По результатам ранее проведенных исследований $[1,2,3]$ значение коэффициента $X$ для воды равнинных рек и озер равно $X=(4,0 \pm 0,2) \cdot 10^{-5}$.

Экологическая техноемкость поверхностных вод соответствует предельно допустимому значению поступления загрязняющих веществ (естественного и антропогенного происхождения). При этом уровень загрязнения в первую очередь зависит от величины коэффициента относительной опасности примесей $A_{\text {пв}}$, содержащихся в поверхностных водах, значение которой определяется по данным фактического или предполагаемого их поступления в водную среду и их токсичности. Отсутствие информации по поступающим в водные объекты загрязняющим веществам создают определенные сложности при установлении значений $A_{П в}$, в связи с этим, по рекомендациям [1], при отсутствии конкретных данных о количестве и составе примесей приняты средние значения $A_{\text {IIB }}=0,3$.

По приведенной методике и на основании воднобалансовых расчетов была определена удельная экологическая техноемкость суммарного годового стока разных территорий Западной Сибири (таблица 3) и их широтная зависимость по 132 метеостанциям.

Удельное значение экологической емкости поверхностных вод территории $e_{n в}=E_{I B} / F$ (где $F-$ площадь водосбора водного объекта) определена по экологической емкости поверхностных вод $E_{\text {Пв }}$ (для изученных рек), которая в свою очередь определяется по уравнению [3]:

$$
E_{\text {IIB }}=W \cdot c \cdot f,
$$

где $E_{\text {Пв }}$ - экологическая емкость поверхностных вод территории, т/год;

$W$ - среднегодовой объем воды в поверхностных водотоках и водоемах территории $\left(\mathrm{KM}^{3}\right)$;

$c$ - содержание (плотность) экологически значимого элемента, в данном случае для воды (плотность воды 109) т/км

$f$ - параметр, характеризующий скорость обновления объема (1/год), для водных ресурсов территории $f=\left(W_{m}+W_{c m}\right) / W,\left(W_{\mu}\right.$ и $W_{c m}-$ соответственно объемы местного стока и объем воды, поступающей с сопредельных территорий, км³).

Выполненные расчеты показали, что удельная экологическая техноемкость годового стока на территории Западной Сибири варьирует от 0,13 до 
4,24 усл. т/км² водосборной площади и представляет собой удельную предельно допустимую эмиссию загрязняющих веществ на 1 км² $^{2}$.

Несмотря на определяющее влияние зональных факторов на территориальное распределение величины $t_{n \varepsilon}$ (рис.) отчетливо прослеживается влияние других (отличных от зональных) факторов, которые более благоприятно влияют на условия формирования стока по отдельным широтам. Особенно это проявляется в зоне тайги, где значение tпв меняется в 2,5-3,0 раза.

Таким образом, рассчитанные значения удельной экологической техноемкости поверхностных вод Западной Сибири $t_{n \varepsilon}$ численно характеризуют изменяющуюся в пространстве и времени предельно допустимую эмиссию загрязняющих веществ, сформированную в результате совокупного воздействия зональных (климатических) и локальных (особенности, строение поверхности водосбора) факторов.

К основным видам техногенного воздействия на территории Западной Сибири относятся нефтегазодобывающие, нефтеперерабатывающие отрасли, а также строительство продуктопроводов. Данные виды промышленных предприятий относятся к числу рентабельных и перспективных отраслей экономики России, в то же время их производственная деятельность представляет определенную опасность на экологическое состояние окружающей среды.

Строительство новых транспортных путей, создание сервисных предприятий на трассах магистрального трубопроводного транспорта, участки газопроводов в рамках логистических схем переработки и транспортировки энергетических и минерально-сырьевых ресурсов, доставки продовольствия неизбежно приведут к усилению антропогенной нагрузки на окружающую среду. Поэтому, наряду с определением значений экологической техноемкости оценка геоэкологической устойчивости экосистем Западной Сибири является объективной необходимостью.

Под геоэкологической устойчивостью обычно понимается свойство, внутренне присущее экосистеме, характеризующее ее способность выдерживать изменения, создаваемые внешними воздействиями, оказывать сопротивление внешним воздействиям и сохранять способность к самовосстановлению. Очевидно, что в экосистеме преобладание внутренних взаимодействий над внешними, способствует ее самосохранению.

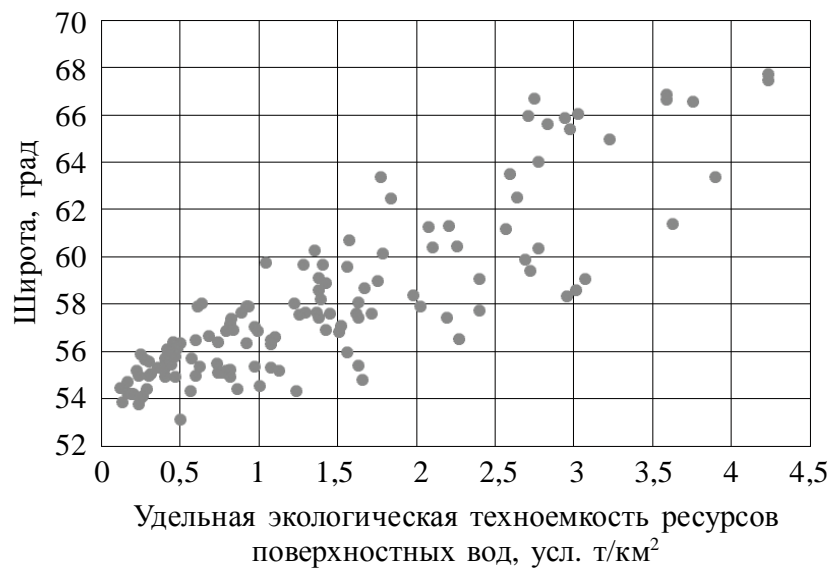

Puc. Широтное изменение удельной экологической техноемкости поверхностных вод $t_{n 6}$ на территории Западной Сибири

Для обеспечения устойчивого состояния геосистем необходимо, чтобы техногенная нагрузка $(M)$ не превышала экологическую техноемкость $(T)$, в виде $M \leq T$. Состояние устойчивости экосистемы выражается отношением $M / T=K$ - так называемым коэффициентом устойчивости. В случае равенства $M=T$, а, следовательно, и $K=1,0$ состояние геосистемы приобретает свое предельное значение (неустойчивое равновесие), когда нарушение любого компонента экосистемы может привести к выходу из предельного равновесия $(K>1,0)$, что чревато ухудшением функциональных свойств с нежелательными последствиями. В связи с этим, при определении пороговых величин состояния экосистем предельное значение коэффициента $K$ необходимо назначать меньше единицы для обеспечения запаса устойчивости (например, $K \leq 0,7)$.

Таким образом, экологическая устойчивость водосборного бассейна в полной степени зависит от результата взаимодействия как природных, так и антропогенных процессов.

\section{ЗАКЛЮЧЕНИЕ}

1. Полученные расчетным путем результаты необходимо учитывать при нормировании антропогенной нагрузки, как на речные бассейны, так и на части бассейнов, находящихся в пределах административных субъектов с целью обеспечения рационального использования и охраны водных ресурсов.

2. Для обеспечения устойчивого состояния геосистем Западной Сибири необходимо, чтобы техногенная нагрузка не превышала экологическую техноемкость. 
3. При определении пороговых величин состояния экосистем, для обеспечения запаса их устойчивости, предельноезначение коэффициента устойчивости необходимо назначать меньше единицы.

\section{СПИСОК ЛИТЕРАТУРЫ}

1. Акимова Т. А. Основы экоразвития / Т. А. Акимова, В. В. Хаскин. - Москва : Издательство Российской экономической академии, 1994. - 312 с.

2. Белоненко Г. В. Эколого-географические условия водопользования в Западной Сибири / Г. В. Белоненко, Н. Б. Попова // Водное хозяйство России: проблемы, технологии, управление. - 2007. - № 3. - С. 25-32.

3. Попова Н. Б. Эколого-географические условия природопользования в зоне влияния Транссибирской магистрали (Западная Сибирь) / Н. Б. Попова. - Новосибирск : Издательство СГУПСа, 2001. - 182 с.

4. Попова Н. Б. Оценка эколого-географических параметров ландшафтных провинций Западно-Сибирского Севера / Н. Б. Попова, Н. Л. Ряполова // Вестник СГУГиТ. - 2017. - Т. 22, № 3. - С. 228-239.

5. Схема комплексного использования и охраны водных объектов бассейна реки Иртыш. Книга 1. Об-

Тусупбеков Жанболат Ашикович

кандидат географических наук, доцент кафедры природообустройства, водопользования и охраны водных ресурсов, Омского государственного аграрного университета имени П.А. Столыпина, г. Омск, E-mail: gggkiovr@mail.ru

\section{Ряполова Наталья Леонидовна}

кандидат географических наук, доцент кафедры природообустройства, водопользования и охраны водных ресурсов, Омского государственного аграрного университета имени П.А. Столыпина, г. Омск, E-mail: natalyaan1986@mail.ru щая характеристика речного бассейна. - URL: http:// nobwu.ru/index.php/ndvskiovo

\section{REFERENCES}

1. Akimova T. A. Osnovy ekorazvitiya / T. A. Akimova, V. V. Khaskin. - Moskva : Izdatel'stvo Rossiyskoy ekonomicheskoy akademii, 1994. $-312 \mathrm{c}$.

2. Belonenko G. V. Ekologo-geograficheskie usloviya vodopol'zovaniya v Zapadnoy Sibiri / G. V. Belonenko, N. B. Popova // Vodnoe khozyaystvo Rossii: problemy, tekhnologii, upravlenie. - 2007. - № 3. - S. 25-32.

3. Popova N. B. Ekologo-geograficheskie usloviya prirodopol'zovaniya v zone vliyaniya Transsibirskoy magistrali (Zapadnaya Sibir') / N. B. Popova. - Novosibirsk : Izdatel'stvo SGUPSa, 2001. - $182 \mathrm{c}$.

4. Popova N. B. Otsenka ekologo-geograficheskikh parametrov landshaftnykh provintsiy Zapadno-Sibirskogo Severa / N. B. Popova, N. L. Ryapolova // Vestnik SGUGiT. - 2017. - T. 22, № 3. - S. 228-239.

5. Skhema kompleksnogo ispol'zovaniya i okhrany vodnykh ob"ektov basseyna reki Irtysh. Kniga 1. Obshchaya kharakteristika rechnogo basseyna. - URL: http://nobwu.ru/ index.php/ndvskiovo

Tusupbekov Zhanbolat Ashikovich

Candidate of Geographical Sciences, Associate Professor, Department of Environmental Management, Water Use and Water Resources Protection, Omsk State Agrarian University named after P. A. Stolypin, Omsk, E-mail: gggkiovr@mail.ru

Ryapolova Natalia Leonidovna

Candidate of Geographical Sciences, Associate Professor, Department of Environmental Management, Water Use and Water Resources Protection, Omsk State Agrarian University named after P. A. Stolypin, Omsk, E-mail: natalyaan1986@mail.ru 